\title{
First fossil record of polypore fungus beetles from Lower Cretaceous amber of France
}

Carmen Soriano, Darren Pollock, Didier Néraudeau, Andre Nel, and Paul Tafforeau

Acta Palaeontologica Polonica 59 (4), 2014: 941-946 doi: http://dx.doi.org/10.4202/app.2012.0074

The first fossil genus and species of Tetratomidae (Coleoptera) is described, from the Lower Cretaceous amber deposits of France. The new genus represents the first insect to be recognized inside an opaque piece of amber, through the use of propagation phase contrast X-ray microtomography using synchrotron radiation. This new finding proves the capabilities of this imaging technique in amber inclusions, as well as increases the knowledge of fossil tenebrionoids, a group scarcely recognized in the Cretaceous fossil record.

Key words: Coleoptera, Tetratomidae, amber, propagation phase contrast X-Ray microtomography, synchrotron, Cretaceous, Charentes, France.

Carmen Soriano [carmen.soriano@gmail.com] and Paul Tafforeau [paul.tafforeau@esrf.fr

], European Synchrotron Radiation Facility, 6 rue Jules Horowitz, 38043

Grenoble, France; Darren Pollock [darren.pollock@enmu.edu], Department of Biology, Eastern New Mexico University, NM88130

Portales, USA; Didier Néraudaeu [didier.neraudeau@univ-rennes1.fr], Géosciences

Rennes and CNRS UMR 6118, Campus de Beaulieu, bâtiment 15, 263 Avenue du

Général Leclerc, 35042 Rennes Cedex, France; Andre Nel [anel@mnhn.fr], CNRS UMR 7205, Muséum National d'Histoire Naturelle, CP50, Entomologie, 45 Rue Buffon, 75005 Paris, France.

This is an open-access article distributed under the terms of the Creative Commons Attribution License (for details please see creativecommons.org), which permits unrestricted use, distribution, and reproduction in any medium, provided the original author and source are credited. 
Forif Full text $(265.3 \mathrm{kB})$ 